\title{
BADANIE EWOLUCJI STANU TECHNICZNEGO BUDYNKU
}

\begin{abstract}
Perspektywa utrzymania budynków mieszkalnych w odpowiednim stanie technicznym narzuca zadania optymalnego planowania prac remontowych, a prawidłowe opracowanie zakresu i programu remontu wymaga ustalenia diagnozy. Diagnostyka stanowi podstawę właściwie prowadzonej działalności remontowej w każdym obiekcie technicznym. Diagnoza obejmuje zadania dotyczące zarówno oceny aktualnego stanu technicznego jak i prognozy rozwoju zmian tego stanu. Prognostyczny opis czasu życia budynku w ujęciu matematycznym pozwala na opracowanie precyzyjnych strategii przywracających odpowiedni poziom efektywności eksploatacyjnych. Opracowany model predykcji właściwości użytkowych budynku pozwala na przewidywanie zmian stanu technicznego budynku. W artykule przedstawiona jest problematyka badania ewolucji stanu technicznego wykonanego w technologii tradycyjnej. Budynek i jego elementy składowe w każdej chwili użytkowania znajdują się w pewnym stanie technicznym, a zmiany stanu technicznego traktuje się jako ciąg stanów uporządkowanych według wartości zmiennej czasowej. W artykule zaprezentowana jest także ocena zgodności zaproponowanego modelu z wynikami kontroli okresowych budynków w Żarach.
\end{abstract}

Słowa kluczowe: stopień zużycia, szereg czasowy, predykcja, rozkład czasu życia

\section{Wprowadzenie}

Diagnostyka stanowi ważną dziedzinę wiedzy umożliwiającą w każdym okresie życia obiektu budowlanego wiarygodne stwierdzenie jaki jest jego stan techniczny [2]. Celem diagnostyki są badania i ocena stanu technicznego oraz przewidywanie rozwoju ich zmian [9].

Obiekty budowlane podczas użytkowania podlegają ciągłym procesom destrukcyjnym o zróżnicowanym przebiegu. W miarę upływu czasu następuje obniżanie ich właściwości użytkowych, a częściowe przywrócenie następuje w wyniku napraw. Zgodnie $\mathrm{z}$ wymogami normowymi [14], [15], [16] należy opracować program ekspozycji starzenia uwzględniający najbardziej istotne mechanizmy degradacji. Model degradacji w rozumieniu PSLDC - Predicted

\footnotetext{
${ }^{1}$ Beata Nowogońska, Uniwersytet Zielonogórski, Wydział Budownictwa, Architektury i Inżynierii Środowiska, ul. Szafrana 1, 65-516 Zielona Góra, tel. 68 3282290, b.nowogonska@ib.uz.zgora.pl
} 
Service Life of a Component - rozkład przewidywanego użytkowania komponentu [14] należy ustalić uwzględniając zależność właściwości użytkowe - czas stosując syntezowanie, modelowanie lub interpolację/ekstrapolację. PSLDC powinien być wyliczony z zależności właściwości użytkowe - czas w wyniku podstawienia określonego liczbowo wymagań użytkowych, wyrażonych w postaci cech właściwości użytkowych lub wskaźników degradacji. Wartość PSLDC jest określona zależnością właściwości użytkowe - czas dla krytycznej właściwości uznanej za graniczną właściwość krytyczną. Zależność właściwości użytkowe - czas jest nieliniową funkcją czasu.

W opracowaniu modelu ewolucji stanu technicznego budynku, oprócz identyfikacji aktualnego stanu, należy również rozwiązać zadanie prognozowania stanu technicznego polegające na przewidywaniu zmian, które zaistnieją $\mathrm{w}$ przyszłości $w$ chwilach $t_{p} \geq t_{d}\left(t_{d}\right.$ - termin diagnozy, $t_{p}$ - jedna $z$ chwil $w$ przyszłości). Zgodnie z zasadami ekonometrii procesy prognozowania obejmują sposób przetworzenia informacji o przeszłości zjawiska oraz sposób przejścia od informacji przetworzonej do prognozy [3], [4]. Przewidywanie składa się z dwóch faz: fazy diagnozowania przeszłości i fazy określania przyszłości. Dane i informacje są retrospektywne, dotyczą przeszłości zjawiska i prospektywne, dotyczące przyszłości zjawiska. Diagnostyka przeszłości odbywa się przez budowę modelu, który odwzorowuje zachowanie rzeczywistego obiektu w celach poznawczych. Sposób przejścia od informacji przetworzonej do prognozy jest definiowany regułą prognozy. Jedną z trzech głównych reguł jest reguła podstawowa, a jej szczególny przypadek to reguła prognozy nieobciążonej. Reguła ta używana jest, gdy przyjmuje się stochastyczne założenia o mechanizmie generującym informacje. Stosowana jest wtedy, gdy model, trafnie opisujący przeszłość będzie również aktualny w czasie, dla którego wyznacza się prognozę. Reguła ta jest użyteczna dla prognozowanych zjawisk o dużej inercji, z powolnymi zmianami ilościowymi. W przypadku prognozy stanu technicznego budynku reguła ta wydaje się najbardziej prawidłową.

\section{Metoda prognozowania}

Podstawą wyboru metody prognozowania są przesłanki prognostyczne oraz właściwości metod. Przesłanki prognostyczne obejmują hipotezy badawcze określające wstępnie mechanizm rozwojowy prognozowanego zjawiska. W prognozowaniu ekonometrycznym stosowane są różne metody prognozowania $\mathrm{m}$. in. szeregi czasowe [4]. Szereg czasowy jest realizacją procesu stochastycznego, którego dziedziną jest czas, jest ciągiem informacji uporządkowanych w czasie. Głównym jego założeniem jest korzystanie w diagnozowaniu przyszłości zjawiska z informacji o dotychczasowym kształtowaniu się zmiennej prognozowanej. Informacje mogą mieć postać jedno- lub wielowymiarowego szeregu czasowego. W modelach tych czas reprezentuje wszystkie czynniki wpływające na zmienne. Prognoza może być wyznaczana na okres lub moment następujący 
bezpośrednio po ostatniej chwili obserwacji, na wybraną chwilę późniejszą lub na wszystkie chwile. Główną przesłanką prognozowania na bazie szeregów czasowych jest wyznaczenie prognozy przy założeniu, że charakter zjawisk z przeszłości będzie taki jak w przyszłości, czyli nie nastąpią zmiany.

Zarówno cechy stanu technicznego jak i sygnały diagnostyczne tego stanu zmieniają się w sposób ciągły w czasie, jedynie w przypadku wykonania prac remontowych zmiana jest skokowa. Czasowa historia zmienności cech jest dana w postaci uporządkowanych w czasie ciągów wartości liczbowych określonych terminem szeregu czasowego. Podstawą ustalenia kolejności jest liczba lat użytkowania budynku. Wymaganiem dla szeregu czasowego jest żądanie stałej wielkości tzw. kroku czasowego w tym szeregu.

Stany techniczne, w których może znaleźć się budynek tworzą zbiór $\mathrm{W}=\left\{\mathrm{w}_{\mathrm{k}}, \mathrm{k}=1,2, . ., \mathrm{K}\right\}$, a konkretny stan $\mathrm{w}_{\mathrm{k}}$ jest wyznaczony przez niezależne cechy stanu $z_{\mathrm{j}}$. Liczba stanów obiektu zależy od wymagań i dlatego, zgodnie z obowiązującymi zasadami oceny stanu technicznego [13], przyjęto 5 stanów budynku (dobry, zadowalający, średni, mierny, zły). Stan $w_{\mathrm{k}}$ będzie znany jeśli będą znane cechy stanu $z_{j}, j=1,2, . ., J$.

\section{Model szeregu czasowego}

Stan techniczny wszystkich elementów budynków mieszkalnych zmienia się w czasie jego użytkowania. Zmiany te, dla pojedynczego elementu budynku np. ścian zewnętrznych, opisane jako jednowymiarowy szereg czasowy zmiennej $Z_{\mathrm{j}}$ (Z- stopień zużycia elementu) uporządkowane są według wartości zmiennej czasowej $\mathrm{j}(\mathrm{j}=1, \ldots, \mathrm{J})$. Przyjęto horyzont prognozy - 100-letni okres użytkowania budynku oraz zmiany stanu technicznego - skok czasowy - określane w 5-letnich odstępach czasu $(0,5,10,15, \ldots, 100$ rok użytkowania).

Reguła prognozowania została ustalona w oparciu o modele opisujące zmiany niezawodności urządzeń technicznych. Do modelowania sytuacji w analizie przeżycia jako rozkład zmiennej losowej czasu zdatności obiektów stosuje się rozkład Weibulla [5], [6], [7], [8], [9], [12]. Szczególnym przypadkiem rozkładu Weibulla jest rozkład wykładniczy, który jest najczęściej stosowany w analizie czasu życia urządzeń [7], [9]. Jednak cechą charakterystyczną rozkładu wykładniczego jest stała intensywność uszkodzeń, czyli wpływ procesów zużycia jest pomijalny. W prognozie stanu technicznego budynku, kiedy zużycie obiektu wraz z upływem czasu jest uznawane za istotną przyczynę awaryjności, bardziej trafnymi zależnościami są oparte na rozkładzie Rayleigha. Rozkład Rayleigha jest również szczególnym przypadkiem rozkładu Weibulla, gdzie parametr kształtu $\alpha=2$. Rozkład ten występuje wtedy, kiedy zużycie obiektu z upływem czasu jest główną przyczyną awaryjności [5], [8], [12].

Wszystkie budynki i ich elementy składowe podczas eksploatacji ulegają zużyciu, a rozkład Rayleigha stosuje się w przypadkach, gdy zużycie obiektu 
rośnie wraz z upływem czasu użytkowania [8]. Funkcja $\mathrm{R}(t)$ opisująca przebieg zmian właściwości użytkowych w czasie $t$ dla okresu trwałości $\mathrm{T}_{\mathrm{R}}$, oparta na rozkładzie Rayleigha, stanowiąca regułę prognozowania jest określona wzorem (1).

$$
\mathrm{R}(t)=\exp \left[-\left(t / \mathrm{T}_{\mathrm{R}}\right)^{2}\right]
$$

Każdy element w budynku ma swoje zadanie. Najbardziej istotny wpływ mają elementy pełniące podstawowe funkcje w czasie użytkowania. Inne elementy pomocnicze wpływają w mniejszym stopniu na ewolucję stanu technicznego obiektu, a ich wpływ wynika przede wszystkim z faktu, że uszkodzenia elementów pomocniczych mogą powodować zmiany parametrów elementów podstawowych. W wyznaczaniu zmian właściwości użytkowych całego budynku $R_{B}(t)$ uwzględnione zostały intensywności wpływu elementów składowych w postaci skali wag elementów $A_{i}$ wg [1], a okresy trwałości elementów wg [11]. W określeniu ewolucji stanu technicznego budynku $\mathrm{R}_{\mathrm{B}}(t)$, którą określa zależność (2), wykorzystane zostały predykcje elementów składowych $\mathrm{R}_{\mathrm{i}}(\mathrm{t})$, wyznaczone wg wzoru (1). Uzyskane wyniki przedstawione są na Rysunku 1.

$$
\mathrm{R}_{\mathrm{B}}(\mathrm{t})=\sum_{\mathrm{i}=1}^{\mathrm{n}}\left[\mathrm{A}_{\mathrm{i}} x \mathrm{R}_{\mathrm{i}}(t)\right]
$$

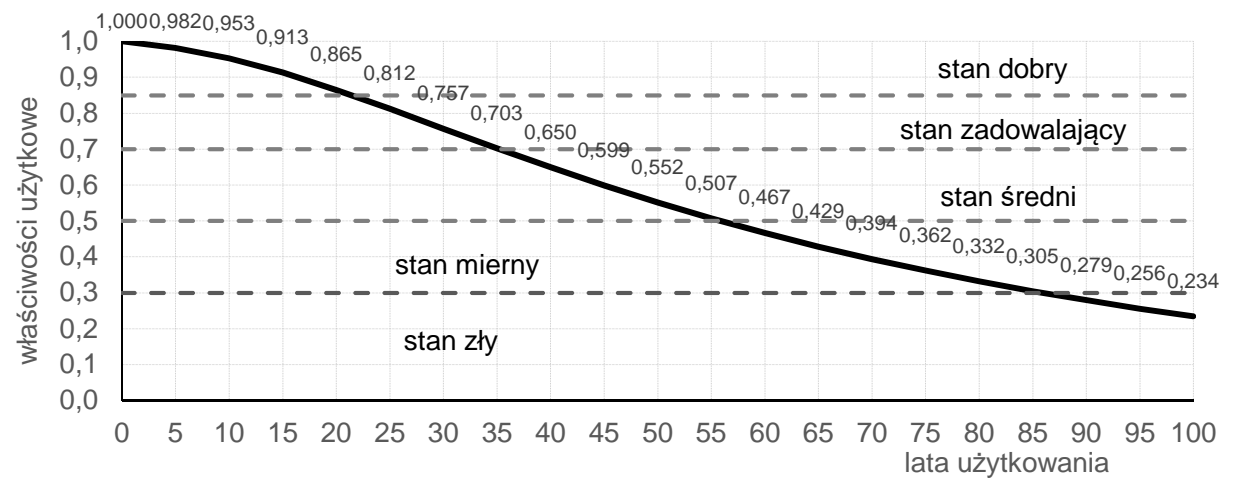

Rys. 1. Ewolucja zmian stanu technicznego budynku

Fig. 1. The investigation of building technical state

\section{Ocena dokładności prognozy}

W analizie zmian niezawodności urządzeń [7] stopień zużycia $S_{Z}$ uzależniany jest od intensywności uszkodzeń $\lambda(t)$ w sposób (3): 


$$
\mathrm{S}_{\mathrm{z}}(t)=\int_{0}^{t} \lambda(t) \mathrm{dt}
$$

Intensywność uszkodzeń w przypadku rozkładu Rayleigha opisuje zależność:

$$
\lambda(t)=2 t / \mathrm{T}_{\mathrm{R}}^{2} t^{2}
$$

W oparciu o powyższe zależności, stopień zużycia jest funkcją zależną od czasu:

$$
\mathrm{S}_{\mathrm{z}}(t)=t^{2} / \mathrm{T}_{R}^{2}
$$

Zgodnie z regułą (5) zostały wyznaczone predykcje zużycia ścian murowanych $\mathrm{z}$ cegły. Okres trwałości ścian $\mathrm{T}_{\mathrm{R}}$ przyjęto taki, jaki jest podawany w literaturze np. w [11], [13], dla ścian murowanych z cegły od 130 do 150 lat.

Zbadane zostały również stopnie zużycia ścian w istniejących użytkowanych budynkach mieszkalnych. Materiał badawczy obejmował 60 budynków mieszkalnych wykonanych $\mathrm{w}$ technologii tradycyjnej, zlokalizowanych w Żarach. Budynki poddane zostały ocenie stanu technicznego w roku 2005, a później ponownie w roku 2010 i 2015 . Zostały określone stopnie zużycia technicznego elementów składowych budynków, między innymi ścian nośnych [10].

Średnie wartości stopnia zużycia ścian w budynkach [10] uporządkowane zostały w ciąg wartości zmiennej czasu, która oznacza długość użytkowania budynków. Wartości stopnia zużycia technicznego stanowią zbiór obserwacji statystycznych charakteryzujących zmiany poziomu zjawiska w czasie.

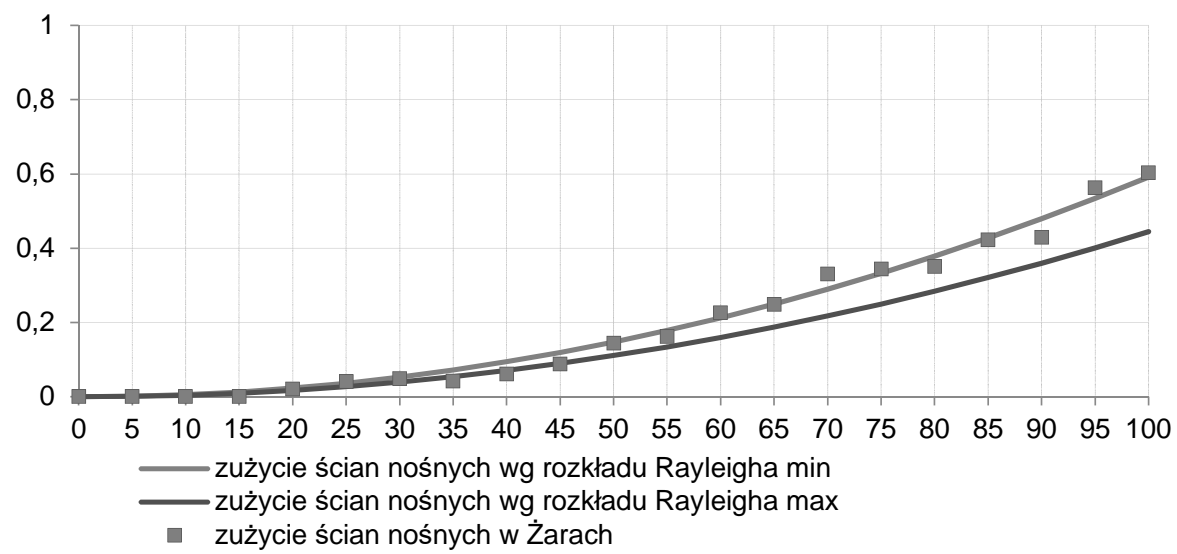

Rys. 2. Predykcje stopnia zużycia ścian murowanych oraz średnie wartości stopnia zużycia ścian, będące wynikiem kontroli okresowych budynków zlokalizowanych w Żarach

Fig. 2. Predictions of the degree of wear of masonry walls as well as average values of the degree of wall wear resulting from the periodic inspection of buildings located in Żary 
Wartość prognostyczna metody może być określona ex ante, czyli w chwili wyznaczania prognozy lub ex post, czyli po upływie czasu, na który prognoza była wyznaczona. Błąd prognozy ex ante jest różnicą między rzeczywistą wartością zmiennej $\mathrm{S}_{\mathrm{z}} \mathrm{W}$ chwili $t$ a prognozą na tę chwilę. Błąd $\mathrm{V}_{\mathrm{t}}$ jest funkcją różnicy między rzeczywistą wielkością $\mathrm{y}_{\mathrm{t}}$ a prognozą $\mathrm{y}_{\mathrm{t}}{ }^{*}, \mathrm{~V}_{\mathrm{t}}$ oznacza progową wartość błędu zadaną np. przez odbiorcę prognozy:

$$
\mathrm{V}_{\mathrm{t}}=\mathrm{f}\left(\mathrm{y}_{\mathrm{t}}-\mathrm{y}_{\mathrm{t}}^{*}\right) \leq \mathrm{V}_{\mathrm{t}}^{*}
$$

Tabela 1. Średnie wartości zużycia ścian nośnych budynków w Żarach oraz prognozowane wartości stopnia zużycia technicznego ścian nośnych, na podstawie [10]

Table 1. Average values of wear of construction walls of buildings in Żary and predicted values of the degree of technical wear of construction walls, based on [10]

\begin{tabular}{|c|c|c|c|c|c|c|c|}
\hline \multirow{2}{*}{$\begin{array}{c}\text { Kolejne lata } \\
\text { użytkowania }\end{array}$} & \multicolumn{3}{|c|}{$\begin{array}{c}\text { Stopień zużycia ścian w } \\
\text { budynkach w Żarach }\end{array}$} & \multicolumn{3}{|c|}{$\begin{array}{c}\text { Predykcje stopnia zużycia wg } \\
\text { rozkładu Rayleigha }\end{array}$} & $\begin{array}{c}\text { Bezwzględny } \\
\text { błąd prognozy }\end{array}$ \\
\cline { 2 - 8 } & 2005 & 2010 & 2015 & $\min$ & $\max$ & średnio & $\mathrm{V}_{\mathrm{t}}$ \\
\hline 0 & bd & bd & bd & 0 & 0 & 0,0000 & - \\
\hline 5 & 0,0000 & bd & bd & 0,0011 & 0,0015 & 0,0013 & $-0,0013$ \\
\hline 10 & 0,0020 & 0,0018 & bd & 0,0044 & 0,0059 & 0,0052 & $-0,0033$ \\
\hline 15 & 0,0120 & 0,0124 & 0,0128 & 0,0100 & 0,0133 & 0,0117 & 0,0007 \\
\hline 20 & 0,0240 & 0,0238 & 0,0242 & 0,0178 & 0,0237 & 0,0208 & 0,0032 \\
\hline 25 & 0,0420 & 0,0303 & 0,0400 & 0,0278 & 0,0370 & 0,0324 & 0,0050 \\
\hline 30 & 0,0460 & 0,0462 & 0,0464 & 0,0400 & 0,0533 & 0,0467 & $-0,0005$ \\
\hline 35 & 0,0660 & 0,0664 & 0,0662 & 0,0544 & 0,0725 & 0,0635 & 0,0027 \\
\hline 40 & 0,0840 & 0,0842 & 0,0844 & 0,0711 & 0,0947 & 0,0829 & 0,0013 \\
\hline 45 & 0,0910 & 0,0884 & 0,0888 & 0,0900 & 0,1198 & 0,1049 & $-0,0155$ \\
\hline 50 & 0,1550 & 0,1255 & 0,1226 & 0,1111 & 0,1479 & 0,1295 & 0,0049 \\
\hline 55 & 0,1880 & 0,1662 & 0,1802 & 0,1344 & 0,1790 & 0,1567 & 0,0214 \\
\hline 60 & 0,2220 & 0,2002 & 0,2224 & 0,1600 & 0,2130 & 0,1865 & 0,0284 \\
\hline 65 & bd & 0,2888 & 0,2992 & 0,1878 & 0,2500 & 0,2189 & 0,466 \\
\hline 70 & bd & bd & 0,3166 & 0,2178 & 0,2899 & 0,2539 & 0,0627 \\
\hline 75 & 0,3220 & bd & bd & 0,2500 & 0,3328 & 0,2914 & 0,0306 \\
\hline 80 & 0,3280 & 0,3422 & bd & 0,2844 & 0,3787 & 0,3316 & 0,0656 \\
\hline 85 & 0,4200 & 0,4664 & 0,4288 & 0,3211 & 0,4275 & 0,3743 & 0,0641 \\
\hline 90 & 0,4200 & 0,4222 & 0,4262 & 0,3600 & 0,4793 & 0,4197 & 0,0031 \\
\hline 100 & 0,4620 & 0,4488 & 0,4642 & 0,4011 & 0,5340 & 0,4676 & $-0,0093$ \\
\hline & 0,5290 & 0,6002 & 0,5882 & 0,4444 & 0,5917 & 0,5181 & 0,0544 \\
\hline
\end{tabular}


Wartości stopnia zużycia ścian wg rozkładu Rayleigha zostały poddane weryfikacji. Wartości błędu prognozy $\mathrm{V}_{\mathrm{t}}$ zawarte są $\mathrm{w}$ Tabeli 1 . Maksymalny błąd wynosi $6,27 \%$. W prognozowaniu gospodarczym [3] stosowane są kryteria dopuszczalności prognoz. Przyjmuje się, że jeżeli miernik dokładności predykcji ex ante (lub ex post) spełnia nierówność:

- $\mathrm{V}_{\mathrm{t}} \leq 3 \%$, to prognozy są bardzo dokładne;

- $3 \%<\mathrm{V}_{\mathrm{t}} \leq 5 \%$, to prognozy uznawane są za dokładne;

- $5 \%<\mathrm{V}_{\mathrm{t}} \leq 10 \%$, to prognozy mogą być dopuszczalne;

- $\mathrm{V}_{\mathrm{t}}>10 \%$, to prognozy są niedopuszczalne.

W przypadku zaproponowanego modelu predykcji stopnia zużycia ścian nośnych (gdzie $5 \%<\mathrm{Vt} \leq 10 \%$ ), prognozę należy uznać za dopuszczalną.

\section{Podsumowanie}

O praktycznej przydatności danego rozkładu jako matematycznego modelu badania ewolucji stanu technicznego decyduje zgodność tego rozkładu z danymi doświadczalnymi. Wyniki oceny stanu technicznego budynków w Żarach potwierdzają skuteczność zaproponowanej metody badania ewolucji budynku wykonanego w technologii tradycyjnej przez zastosowanie zależności opartych na rozkładzie Rayleigha.

\section{Literatura}

[1] Arendarski J.: Trwałość i niezawodność budynków mieszkalnych. Arkady, Warszawa 1978.

[2] Brunarski L., Runkiewicz L.: Diagnostyka obiektów budowlanych. Materiały konferencyjne 56 Konferencji Naukowej Komitetu Inżynierii Lądowej i Wodnej PAN i PZITB Krynica 2010.

[3] Cieślak M.: Prognozowanie gospodarcze. Wydawnictwo Akademii Ekonomicznej we Wrocławiu, Wrocław 1993.

[4] Galanc T.: Metody wspomagania procesu zarządzania. Część II: Decyzyjne modele liniowe i prognozowanie ekonometryczne. Wyd. Politechniki Wrocławskiej, 1993.

[5] Khelassi, A., Theilliol, D., Weber, P.: Reconfigurability analysis for reliable faulttolerant control design, International Journal of Applied Mathematics and Computer Science, 2011, s. 431-439.

[6] Nowak A. S., Collins K. R.: Reliability of Structures, Mc Graw-Hill Int. Edition, 2000.

[7] Nowakowski T.: Metodyka prognozowania niezawodności obiektów mechanicznych. Oficyna Wydawnicza Politechniki Wrocławskiej, Wrocław, 1999.

[8] Nowogońska B.: Mathematical reliability model of building components by Rayleigh Civil Environmental Engineering Reports, 2014 nr 15, 87-97.

[9] Niziński S.: Elementy diagnostyki obiektów technicznych. Wydawnictwo Uniwersytetu Warmińsko-Mazurskiego, Olsztyn 2001. 
[10] Protokoły okresowej kontroli stanu technicznego budynków mieszkalnych zarządzanych przez Zarządcę Wspólnot Mieszkaniowych „Twój Dom” Żary sporządzone w 2005 r., 2010 r., 2015 r.

[11] Ściślewski Z: Trwałość budowli, Wydawnictwo Politechniki Świętokrzyskiej 1995.

[12] Walpde R. E., Myers R. H.: Probability and Statistics for Engineers and Scientists, Macmillan Publishing Company, London 1985.

[13] Winniczek W.: Wycena budynków i budowli podejściem odtworzeniowym, CUTOB-PZITB, Wrocław 1993.

[14] PN-ISO 15686-1: 2005 Budynki i budowle. Planowanie okresu użytkowania. Część 1: Zasady ogólne.

[15] PN-ISO 15686-2: 2005 Budynki i budowle. Planowanie okresu użytkowania. Część 2. Procedury związane z przewidywanym okresem użytkowania.

[16] PN-ISO 15686-7 Budynki i budowle. Planowanie okresu użytkowania. Część 7: Ocena właściwości użytkowych na podstawie danych z praktyki dotyczących okresu użytkowania.

\section{THE INVESTIGATION OF BUILDING TECHNICAL STATE}

\section{S u m m a r y}

The prospect of maintaining residential buildings in an adequate technical state calls for the optimal planning of renovation work, while proper determination of the scope and program of the renovation requires a diagnosis to be made. Diagnostics is a basis for properly carried out renovation work in every technical object. Technical diagnostics covers issues connected with assessing the technical condition of an object, as well as the possibilities of its continued use. The diagnosis regards issues connected with the assessment of the current condition, as well as prediction of the development of changes in this condition. The prognostic description of the lifespan of a building in the mathematical approach makes it possible to prepare precise strategies returning an appropriate level of operational performance. The prepared model for predicting the performance of a building makes it possible to foresee the technical condition as well as model scenarios of renovation works. Prediction processes cover the means of processing information on the past of the occurrence as well as the means of changing over from processed information to a prediction. Predicting is comprised of two phases: diagnosing the past and determining the future. The building and its components of are characterized by a given technical state at every moment of use. Changes in the technical state are treated as a series of states sorted according to the value of the time variable. The article also presents an assessment of the agreement of the proposed model with empirical data - the results of the periodical inspections of buildings in the town of Żary.

Keywords: degree of wear, time series, prediction, life distribution

Przestano do redakcji: 07.06.2016 $r$.

Przyjęto do druku: 30.06.2016 r.

DOI: $10.7862 /$ rb.2016.4 